\title{
Further investigation of the antiovulatory effects of the antiprogestational steroid RMI 12,936 in the rat
}

\author{
Claire Geddes, K. E. Kendle, Carole W. Shanks and Margaret J. Steven \\ School of Pharmacy, Robert Gordon's Institute of Technology, Schoolhill, \\ Aberdeen AB9 IFR, U.K.
}

\begin{abstract}
Summary. Inhibition of ovulation by RMI 12,936 was associated with suppression of the pro-oestrous peak of hypothalamic dopamine. The antiovulatory effect was not reversed by administration of oestrogen, was partly reversed by progesterone and was fully reversed by oestrogen and progesterone. Hypophysial sensitivity to $\mathrm{LH}$ RH, known to be reduced by RMI 12,936, remained low when ovulation was restored by steroid treatment. Administration of oestrogen did not restore the prooestrous peak of hypothalamic dopamine and ovulation was not induced following administration of L-DOPA in RMI 12,936-treated animals. It was concluded that RMI 12,936 is antioestrogenic as well as antiprogestational, that oestrogen is necessary for induction of full hypothalamic-hypophysial responsiveness to progesterone and that a hypothalamic dopaminergic pathway may have a non-essential role in the control of ovulation possibly associated with increasing hypophysial sensitivity to LH-RH.
\end{abstract}

\section{Introduction}

Administration of RMI 12,936 (17 $\beta$-hydroxy-7 $\alpha$-methylandrost-5-en-3-one) on the 2 nd day of dioestrus in the rat inhibited ovulation, reduced tonic LH levels in serum and blocked the prooestrous LH surge (Kendle, Paterson \& Wilson, 1978). Ovulation was restored by hCG or LHRH but hypophysial sensitivity to LH-RH was less than when ovulation was blocked with sodium pentobarbitone. Hypothalamic dopamine levels increase to a peak value during the day of pro-oestrus (Negro-Vilar, Chiocchio \& Tranezzani, 1977) and dopamine has been shown to facilitate LH release in vivo and in vitro (Schneider \& McCann, 1969, 1970). The present study was therefore undertaken to determine whether inhibition of ovulation by RMI 12,936 could be attributed to hormone antagonism acting by modification of hypothalamic dopaminergic pathways.

\section{Materials and General Methods}

\section{General}

SPF-derived rats of the Sprague-Dawley strain were housed as described previously (Kendle, 1975) with artificial illumination from 08:00 to 20:00 h daily. Vaginal lavages were taken daily and only rats showing at least 2 regular 4 -day oestrous cycles were used in the experiments. The day of pro-oestrus was designated Day $\mathrm{P}$ and that of oestrus Day O; days of dioestrus were Days D1 and D2. Ovulation was detected by macroscopic and microscopic examination of the oviducts to reveal the presence of eggs in the distended ampulla.

Steroids (purchased from BDH (Chemicals) Ltd, Poole, except for RMI 12,936, a gift from Merrell National Laboratories) were suspended in an aqueous vehicle containing $0.25 \%(\mathrm{w} / \mathrm{v})$ sodium carboxymethyl cellulose and 1\%(w/v) 'Tween 80'; hCG (Pregnyl: Organon, Morden) 
and synthetic LH-RH (a gift from Hoechst U.K. Ltd, Hounslow, Middlesex) were dissolved or diluted in saline $(0.9 \%(\mathrm{w} / \mathrm{v})$ sodium chloride solution) before use. Doses were administered subcutaneously in a dose volume of $0.5 \mathrm{ml}$ except as otherwise stated.

\section{Spectrofluorometric assay of hypothalamic dopamine}

The hypothalamus was quickly dissected out from the frozen brain using the method of Glowinski \& Iversen (1966) and weighed on a micro-analytical balance. Extraction of dopamine was by the method of Cox \& Perhach (1973) except that after homogenization in acidified butanol the supernatant was mixed with heptane and $0.1 \mathrm{M}$-hydrochloric acid (in place of water). The acid phase was then assayed fluorometrically as described by Shellenberger \& Gordon (1971). The sensitivity of the assay was the concentration of dopamine giving twice the fluorescence intensity of the tissue blank (made by extracting brain tissue but adding alkaline sulphite reagent before the iodine reagent) and was $16 \mathrm{ng} / 0.5 \mathrm{ml}$ acid phase. The intra-assay coefficient of variation was $10 \%$ and inter-assay variation was not greater than intra-assay variation. The standard dopamine curves were unaltered by the addition of noradrenaline and/or 5 -hydroxytryptamine in concentrations equal to those of dopamine.

\section{Detailed Methods and Results}

\section{Effect of RMI 12,936 on hypothalamic dopamine levels}

Rats, given $2 \mathrm{mg}$ RMI 12,936 at 16:00 h on Day D2, were killed at 12:00, 14:00 or 17:00 h on Day P and control animals, given the vehicle, were killed at 17:00 h on Day D2 and at 10:30, 12:00, 14:00 or 17:00 h on Day P. Eight animals were used at each time of autopsy. Hypothalamic dopamine levels were determined as described above, and compared by using a multiple-range $t$ test. The results given in Table 1 show that the peak of hypothalamic dopamine concentration observed in control animals at 12:00 h on Day $\mathrm{P}$ was inhibited by pretreatment with RMI 12,936 at 16:00 h on Day D2.

Table 1. Hypothalamic dopamine concentrations (mean \pm s.e.m.) in groups of 8 rats killed at various times after treatment with $2 \mathrm{mg}$ RMI 12,936 or vehicle at $16: 00 \mathrm{~h}$ on

Day D2

\begin{tabular}{|c|c|c|c|}
\hline \multirow[b]{2}{*}{ Treatment } & \multicolumn{2}{|c|}{ Time of autopsy } & \multirow{2}{*}{$\begin{array}{l}\text { Hypothalamic dopamine } \\
\text { conc. }(\mu \mathrm{g} / \mathrm{g})\end{array}$} \\
\hline & Hours & Day & \\
\hline \multirow[t]{5}{*}{ Vehicle } & $17: 00$ & D2 & ${ }^{*} 0.65 \pm 0.13$ \\
\hline & $10: 30$ & $P$ & $0.83 \pm 0.13$ \\
\hline & $12: 00$ & $\mathbf{P}$ & $1.79 \pm 0.54$ \\
\hline & $14: 00$ & $\mathbf{P}$ & $0.76 \pm 0.14$ \\
\hline & $17: 00$ & $\mathbf{P}$ & ${ }^{*} 0.35 \pm 0.05$ \\
\hline \multirow[t]{3}{*}{ RMI 12,936 } & $12: 00$ & $\mathbf{P}$ & $* 0.41 \pm 0.09$ \\
\hline & $14: 00$ & $\mathbf{P}$ & ${ }^{*} 0.53 \pm 0.10$ \\
\hline & $17: 00$ & $\mathbf{P}$ & ${ }^{*} 0.25 \pm 0.03$ \\
\hline
\end{tabular}

* Significantly different from peak control value at $12: 00 \mathrm{~h}$ on Day $\mathrm{P}(P<0.05)$ but not significantly different from each other (Multiple range $t$ test after logarithmic transformation.)

\section{Effect of gonadal steroids on ovulation in RMI 12,936-treated rats}

Groups of 8 rats were treated as shown in Table 2. All animals were killed on the morning of Day $\mathrm{O}$ between 09:00 and 12:00 h and examined for evidence of recent ovulation. Numbers of animals ovulating in each group were compared with the Fisher exact test. Treatment with RMI 
12,936 inhibited ovulation, as shown in Table 2 . The effect was fully reversed by administration of oestrogen and progesterone while oestrogen alone was ineffective and progesterone alone only effective in half of the animals tested.

Table 2. Effect of gonadal steroids on the incidence of ovulation in groups of 8 rats after treatment with RMI 12,936

\begin{tabular}{|c|c|c|c|}
\hline \multicolumn{3}{|c|}{ Treatments } & \multirow{2}{*}{$\begin{array}{c}\text { No. of animals } \\
\text { ovulating }\end{array}$} \\
\hline 16:00 h on Day D2 & $17: 00 \mathrm{~h}$ on Day D2 & $13: 00 \mathrm{~h}$ on Day $\mathrm{P}$ & \\
\hline Vehicle & Vehicle & Vehicle & 8 \\
\hline RMI $12,936,2 \mathrm{mg}$ & Vehicle & Vehicle & 0 \\
\hline RMI $12,936,2 \mathrm{mg}$ & Oestradiol, $2 \mu \mathrm{g}$ & Vehicle & 0 \\
\hline RMI $12,936,2 \mathrm{mg}$ & Vehicle & Progesterone, $2 \mathrm{mg}$ & $4^{*}$ \\
\hline RMI 12,936, 2 mg & Oestradiol, $2 \mu \mathrm{g}$ & Progesterone, $2 \mathrm{mg}$ & 8 \\
\hline
\end{tabular}

* Significantly different from vehicle control $(P=0.042)$ and from rats given RMI 12,936 only $(P=0.039)$ (Fisher exact test).

\section{Effect of gonadal steroids on hypophysial sensitivity to $\mathrm{LH}-\mathrm{RH}$}

Three groups of rats were given the following treatments: (1) $2 \mathrm{mg}$ RMI 12,936 at 16:00 h on Day D2; (2) $35 \mathrm{mg}$ sodium pentobarbitone $/ \mathrm{kg}$ by the intraperitoneal route at 15:00 h on Day P; (3) 2 mg RMI 12,936 at 16:00 h, $2 \mu$ g oestradiol at 17:00 h on Day D2 with 2 mg progesterone at 13:00 h and $35 \mathrm{mg} / \mathrm{kg}$ sodium pentobarbitone at 15:00 h on Day P. Various doses of LH-RH were given to animals from each treatment group at 16:00 h on Day P, using 4 or 5 rats for each dose level. Autopsy was between 09:00 and 12:00 h on Day $O$ when the numbers of animals ovulating were determined and the median effective doses of LH-RH were calculated for each treatment by using probit transformation.

The median effective dose $\left(\mathrm{ED}_{50}\right)$ of $\mathrm{LH}-\mathrm{RH}$ needed to induce ovulation was $0.116 \mu \mathrm{g}$ in rats given sodium pentobarbitone, $0.969 \mu \mathrm{g}$ in rats given RMI 12,936 and $0.823 \mu \mathrm{g}$ in rats given RMI 12,936, gonadal steroids and sodium pentobarbitone. Relative potencies of LH-RH were calculated by using the animals given only sodium pentobarbitone as the standard (relative potency 1). In the other two groups the relative potencies were 0.117 and 0.138 respectively. These were significantly different from the standard but not from each other (fiducial limits $0.032-0.368$ and $0.022-0.503$ respectively, $P=0.05$ ).

\section{Effect of oestrogen on hypothalamic dopamine levels in RMI 12,936-treated rats}

The treatments were as shown in Table 3. Five animals from each group were killed at 12:00 h on Day P and a further 5 of the oestrogen-treated animals at 10:30 and 14:00 h on Day $P$. Hypothalamic dopamine levels were determined as described above and compared using a multiple $t$ test. As shown in Table 3, administration of oestrogen to animals given RMI 12,936 did not restore the hypothalamic dopamine peak.

\section{Effect of $\mathrm{L}-D O P A$ on ovulation in RMI 12,936-treated rats}

Groups of 5 rats were given $2 \mathrm{mg}$ RMI 12,936 at 16:00 h on Day D2 and vehicle at 12:00 h on Day P; 2 mg RMI 12,936 at 16:00 h on Day D2 and 100 mg L-DOPA by the intraperitoneal route at 12:00 h on Day $P$ or vehicle on both occasions. The animals were killed between 09:00 and 12:00 h on Day $O$ and the numbers ovulating were determined.

Administration of L-DOPA did not restore ovulation in the RMI 12,936-treated rats. None of the animals given RMI 12,936 or RMI 12,936 and L-DOPA ovulated while all given the vehicle on both occasions did so. 
Table 3. Hypothalamic dopamine concentrations (mean \pm s.e.m.) in groups of 5 rats given various treatments on Day D2

\begin{tabular}{cccc}
\hline \multicolumn{2}{c}{ Treatment on Day D2 } & & Time of autopsy \\
on Day P $(\mathrm{h})$ & $\begin{array}{c}\text { Hypothalamic dopamine } \\
\text { conc. }(\mu \mathrm{g} / \mathrm{g})\end{array}$ \\
\hline $16: 00 \mathrm{~h}$ & $17: 00 \mathrm{~h}$ & & \\
\hline Vehicle & Vehicle & $12: 00$ & $2.307 \pm 0.681$ \\
RMI 12,936 $(2 \mathrm{mg} / \mathrm{rat})$ & Vehicle & $12: 00$ & ${ }^{*} 0.424 \pm 0.027$ \\
RMI 12,936 $(2 \mathrm{mg} / \mathrm{rat})$ & Oestradiol & $10: 30$ & ${ }^{*} 0.783 \pm 0.223$ \\
& $(2 \mu \mathrm{g} / \mathrm{rat})$ & $12: 00$ & ${ }^{*} 0.526 \pm 0.048$ \\
& & $14: 00$ & ${ }^{*} 0.636 \pm 0.120$ \\
\hline
\end{tabular}

\footnotetext{
* Significantly different from vehicle control $(P<0.01)$ but not significantly different from each other (Multiple range $t$ test after logarithmic transformation).
}

\section{Histological examination of ovaries}

Ten rats were given $2 \mathrm{mg}$ RMI 12,936 at 16:00 $\mathrm{h}$ on Day D2 and a further 10 were given the vehicle. Five animals from each group were killed at 17:00 h on Day $P$ and the remaining 5 at 09:00 h on Day $\mathrm{O}$. The ovaries were removed at autopsy and fixed in buffered formol saline. Using a freezing microtome $15 \mu \mathrm{m}$ sections were cut and stained with $1 \%(\mathrm{w} / \mathrm{v})$ aqueous methylene blue. At least 3 sections from each ovary were examined. No difference was apparent between test and control animals killed on Day P. Large follicles were found in all sections from test animals killed on Day $O$ but were not observed in sections of ovaries from the control group killed at this time.

\section{Discussion}

Treatment with RMI 12,936 that inhibits ovulation also inhibits the pro-oestrous peak of hypothalamic dopamine. The anti-ovulatory effect is partly reversed by progesterone and fully reversed by oestrogen and progesterone. RMI 12,936 is known to inhibit progesterone synthesis (Kendle, 1976), probably by acting as an alternative substrate for $\Delta^{5}-3$ ketosteroid isomerase (Taylor \& Kendle, 1978). Oestrogen synthesis also involves enzymic isomerization of $\Delta^{5}-3$ ketosteroids and is therefore likely to be inhibited by RMI 12,936 treatment. Oestrogen is necessary for the development of the facilitatory effect of progesterone on ovulation (Brown-Grant, 1969) and for the induction of hypothalamic progesterone receptors (Kato \& Onouchi, 1977; MacLuski \& McEwen, 1978). The results indicate that treatment with RMI 12,936 reduces oestrogen levels to less than the critical level for these effects in $50 \%$ of treated animals, but full sensitivity to progesterone is obtained by treatment with oestrogen.

Administration of gonadal steroids reversed the inhibition of ovulation following RMI 12,936 treatment but hypophysial sensitivity to LH-RH remained significantly lower than in animals in which ovulation was inhibited with sodium pentobarbitone. Oestrogen (Arimura \& Schally, 1971; Aiyer \& Fink, 1974), progesterone (Aiyer \& Fink, 1974) and LH-RH (Aiyer, Chiappa \& Fink, 1974) increase hypophysial sensitivity to LH-RH. If the administered gonadal steroids do not completely reproduce physiological hormone levels during the preovulatory period a process of hypophysial sensitization may not occur and this would explain why low hypophysial sensitivity persists in these experiments. The role of steroids in modifying the hypophysial response to LH-RH is now being investigated by measurement of serum LH after steroid treatment and $\mathrm{LH}-\mathrm{RH}$ administration.

The hypothalamic dopamine peak occurs in control animals earlier than the time of progesterone administration in the steroid replacement experiments. If this peak were restored in these experiments it must therefore be an effect of oestrogen and previous work has shown that 
oestrogen can increase dopamine uptake in the anterior hypothalamus (Cardinali \& Gomez, 1977). The results show however that the hypothalamic dopamine peak was not restored by oestrogen treatment and that administration of L-DOPA did not restore ovulation in rats treated with RMI 12,936 although it will do so in rats in which the block is due to inhibition of catecholamine synthesis (Kordon \& Glowinski, 1969). It must therefore be concluded that dopamine has a non-essential role in the control of ovulation, possibly associated with increasing hypophysial sensitivity to LH-RH. Further investigations are being undertaken to determine whether the dopamine peak represents enhanced activity in a stimulatory pathway or reduced amine turnover in an inhibitory pathway.

Previous studies (Kendle et al., 1978) have shown that ovulation may be induced in RMI 12,936-treated rats by administration of LH-RH or hCG. This would suggest that normal follicles were present in the ovary during pro-oestrus and the present histological investigation shows this to be the case. The presence of very large follicles in treated animals on the day of oestrus confirms ovulation failure. Since the treatment is followed by a prolonged period without ovulation it is probable that these large follicles become atretic but further investigation is necessary to establish this.

We thank Dr V. Petrow and Merrell National Laboratories, Division of Richardson Merrell Inc., Cincinnati, Ohio, for the RMI 12,936, and Miss D. J. Baker, Hoechst U.K. Ltd, Hounslow, for the LH-RH.

\section{References}

Aiyer, M.S. \& Fink, G. (1974) The role of sex steroid hormones in modulating the responsiveness of the anterior pituitary gland to luteinizing hormone releasing factor in the female rat. J. Endocr. 62, 533-572.

Aiyer, M.S., Chiappa, S.A. \& Fink, G. (1974) A priming effect of luteinizing hormone releasing factor on the anterior pituitary gland in the female rat. J. Endocr. 62, 573-588.

Arimura, A. \& Schally, A.V. (1971) Augmentation of pituitary responsiveness to LH-releasing hormone (LH-RH) by oestrogen. Proc. Soc. exp. Biol. Med. 136, 290-293.

Brown-Grant, K. (1969) The induction of ovulation by ovarian steroids in the adult rat. $J$. Endocr. 43, 553562.

Cardinali, D.P. \& Gomez, E. (1977) Changes in hypothalamic noradrenaline, dopamine, and serotonin uptake after oestradiol administration to rats. J. Endocr. 73, 181-182.

Cox, R.H. \& Perhach, J.L. (1973) A sensitive rapid, and simple method for the simultaneous spectrophotofluorometric determinations of norepinephrine, dopamine, 5-hydroxytryptamine and 5-hydroxyindoleacetic acid in discrete areas of the brain. $J$. Neurochem. 20, 1777-1780.

Glowinski, J. \& Iversen, L.L. (1966) Regional studies of catecholamines. J. Neurochem. 13, 655-669.

Kato, J. \& Onouchi, T. (1977) Specific progesterone receptors in the hypothalamus and anterior hypophysis of the rat. Endocrinology 101, 920-928.

Kendle, K.E. (1975) Some biological properties of RMI 12,936 , a new synthetic antiprogestational steroid. $J$. Reprod. Fert. 43, 505-513.

Kendle, K.E. (1976) Effects of RMI 12,936, a synthetic antiprogestational steroid, in the rat. J. Reprod. Fert. 48, 159-166.
Kendle, K.E., Paterson, J.R. \& Wilson, C.A. (1978) Effects of RMI 12,936, a synthetic antiprogestational steroid, on the oestrous cycle and ovulation in the rat. J. Reprod. Fert. 53, 363-368.

Kordon, C. \& Glowinski, J. (1969) Selective inhibition of superovulation by blockade of dopamine synthesis during the critical period in the immature rat. Endocrinology 85, 924-931.

MacLuski, N.J. \& McEwen, B.S. (1978) Oestrogen modulates progestin receptor concentrations in some rat brain regions but not in others. Nature, Lond. 274, 276-278.

Negro-Vilar, A., Chiocchio, S.R. \& Tranezzani, J.H. (1977) Changes in catecholamine content of the median eminence precede the pro-oestrous surges of luteinizing hormone and prolactin. J. Endocr. 75, 339-340.

Schneider, H.P.G. \& McCann, S.M. (1969) Possible role of dopamine as a transmitter to promote discharge of luteinizing hormone releasing factor. Endocrinology 85, 121-132.

Schneider, H.P.G. \& McCann, S.M. (1970) Release of LH releasing factor (LRF) into the peripheral circulation of hypophysectomized rats by dopamine and its blockage by oestradiol. Endocrinology 87, 249253.

Shellenberger, M.K. \& Gordon, J.H. (1971) A rapid simplified procedure for simultaneous assay of noradrenaline, dopamine and 5-hydroxytryptamine from discrete brain areas. Analyt. Biochem. 39, 356372.

Taylor, R.B. \& Kendle, K.E. (1978) Use of HPLC to determine the effect of $17 \beta$-hydroxy-7 $\alpha$-methylandrost-5-en-3-one (RMI 12,936) on production of progesterone by rat ovarian homogenate. Acta endocr., Copenh. 88, 157-163.

Received 5 December 1978 